\title{
A GEOGRAFIA E AS TEMÁTICAS FÍSICO-NATURAIS NO ENSINO
}

\author{
Edjander Araújo da Costa ${ }^{\mathrm{I}}$ \\ Elaine Gomes do Amaral ${ }^{2}$
}

RESUMO: Este artigo apresenta uma reflexão das temáticas físico-naturais como conteúdo de ensino da Geografia Escolar, buscando destacar a dimensão integradora da disciplina e a superação de uma visão tradicional que ainda existe na Geografia, objetivando analisar a relação dessas duas visões. A metodologia consistiu na revisão bibliográfica e análise de questionários, a fim de compreender a percepção de discentes quanto à temática central. A proposta planejada no contexto de disciplinas de ensino da Geografia, por docentes que vivenciam o exercício de relacionarem teoria à prática e a busca por estratégias didáticas metodológicas inovadoras, constatou a importância da postura e ações pedagógicas frente ao tratamentodas temáticas físico-naturais, evidenciando as suas relações com o cotidiano, como cerne para o fortalecimento da Geografia Escolar, que vai da ausência de reflexão a respeito do contexto político-epistemológico a uma versão mais atualizada do cotidiano.

Palavras-chave: Ensino. Geografia. Escolar. Método Pedagógico

\section{INTRODUÇÃO}

A Geografia Física enquanto conhecimento científico surge entre os séculos XVIII e XIX sob forte influência dos naturalistas, contudo como um ramo específico da Geografia, ela se efetiva com o surgimento da Geografia Regional de Vidal de La Blache. As principais bases da Geografia como ciência e, por conseguinte, da Geografia Física estão ancoradas em descobrimentos de naturalistas europeus. Entretanto, são os naturalistas europeus Kant, Humboldt e Ritter os mais importantes no desenvolvimento da Geografia. Inclusive, segundo

${ }^{\mathrm{I}}$ Formação graduada em geografia e pedagogia. Pós- graduação em ensino da geografia.

2 Graduação em Biologia. Técnica de Enfermagem. Unidade de Terapia Intensiva adulto do Hospital de Clínicas. Universidade Federal de Uberlândia 
Mendonça (20II), o termo Geografia Física aparece pela primeira vez no século XVIII, em um livro de Kant.

O conhecimento geográfico foi sendo constituído, ao longo do tempo, fruto de um movimento relacional e complexo da sociedade, influenciado pela dinâmica econômica, política, social e cultural. Assim, em resposta a cada momento histórico, a Geografia foi sendo modelada, tornando-se uma rica e vasta área. Ao considerar a diversidade latente na ciência geográfica não se reafirma dicotomias, mas ressalta-se o todo e as partes que formam este todo, realçando a necessidade das interrelações. As pluralidades são multiplicidades que dialogam entre si, consolidando, portanto, a singularidade e unicidade da ciência geográfica.

As temáticas físico-naturais fazem parte da dimensão de análise da Geografia denominada de Física e são aquelas representadas por conteúdos que objetivam tratar do entendimento dos componentes naturais das paisagens representados por elementos geológicos, geomorfológicos, climáticos, hidrográficos; $\mathrm{da}$ compreensão $\mathrm{da}$ origem $e$ desenvolvimento dos sistemas ambientais.

Sobre o caráter unitário consolidado na Geografia, Claudino-Sales (2004) faz a seguinte ressalva: "Se a Geografia é unitária, porém, quando baseada em geossistemas, ela também o é formalmente acrítica, pois os geossistemas, não consideram a ação dos processos que ocorrem em escala temporal de médio e longo prazo" (CLAUDINO-SALES, 2004, p. 132). Assim, a partir desse momento, os estudos em Geografia Física no Brasil começam a ser influenciados pela Teoria Geossistêmica, onde fatores econômicos e sociais influenciam em tais abordagens numa tentativa de aproximar, inclusive, a Geografia Física de outros sub-ramos da Geografia como a Geografia Crítica. Logo, é por meio das questões ambientais que a Geografia Física tenta superar a dicotomia Física-Humana, inter-relacionando o meio com as atividades humanas 
Conforme Oliveira (2012), no ensino e aprendizagem da Geografia, o entendimento dos fenômenos e problemáticas espaciais em sala de aula demanda um trabalho orientado à seleção e organização de conteúdo, à operacionalização de métodos e procedimentos didáticos que objetivem relacionar o currículo da Geografia Acadêmica às necessidades e preocupações da Geografia Escolar.

Nesse contexto, tidas como temas socialmente relevantes, as temáticas físico-naturais abrangem um caráter próprio para lidar com os problemas ambientais e passam a exigir novas posturas teóricas e metodológicas. Sendo assim, mobilizam reflexões sobre I

\section{r.DESENVOLVIMENTO}

\section{I.IEducação Valorização e Articulação da Geografia na Educação Básica}

[...], educar para a liberdade não é apenas educar os outros, mas também a si mesmo, de forma permanente, aprendendo ao mesmo tempo que se ensina (ou melhor, que se leva os alunos a aprender). Só assim pode-se propiciar aos educandos que se tornem cidadãos plenos, agentes da história, sujeitos autônomos, críticos e criativos (VESENTINI, 2005, p.i4, grifo do autor).

Segundo Cavalcanti (2012, p. 92), "o conhecimento da Geografia Escolar é o

conhecimento construído pelos professores a respeito dessa matéria e constitui fundamento básico para a formulação de seu trabalho docente

A educação precisa ser compreendida como:

Uma educação global que leve o aluno a trabalhar em harmonia e compreensão, a desenvolver padrões de comportamento positivo, criatividade, cooperação, responsabilidade e preocupação com o destino das outras pessoas. Uma educação que respeite os direitos humanos, que favoreça a compreensão mútua e a solução pacífica dos conflitos. (MORAES, 1997).

Assim, os conhecimentos trabalhados em um curso de licenciatura em Geografia são basilares na construção e compreensão gradativa e relacional do conhecimento da ciência geográfica. No entanto, as ações de pensar e tratar pedagogicamente os temas e conteúdos favorece a compreensão de como os mesmos podem ser articulados em uma sala de aula, nos mais diversos segmentos de ensino. Acredita-se, portanto, neste trabalho, que a construção da 
Geografia Escolar vai ocorrendo gradativamente, a partir das experiências diversas e cotidianas.

Neste ínterim, outra questão essencial, defendida pelas autoras, refere-se à maior aproximação entre os ambientes acadêmico e escolar. É a partir do conhecimento da realidade e necessidade da escola que a academia pode estabelecer, por exemplo, discussões mais efetivas para o processo de formação de professores. Não dá mais para pensar na formação de modo desvinculado da realidade efervescente da escola, caso se almeje formar professores que possam contribuir para uma intervenção crítica no/do cotidiano

A educação corresponde, pois, a toda modalidade de influências e interrelações que convergem para a formação de traços de personalidade social e do caráter. (LIBÂNEO, 1994). Segundo Saviani: "Se a educação é mediação, isto significa que ela não se justifica por si mesma, mas tem sua razão de ser nos efeitos que se prolongam para além dela e persistem mesmo após a cessação da ação pedagógica". (1984, p. 80). "O processo educativo é a passagem da desigualdade a igualdade”. (SAVIANI, I984, p. 8I).

\section{I.I A Geografia Escolar e Temáticas Físico-Naturais}

No que se refere ao ensino das disciplinas básicas, D’Ambrosio afirma: “o ensino de qualquer disciplina dos nossos currículos escolares, só se justifica dentro de um contexto próprio, de objetivos bem delineados dentro do quadro das prioridades nacionais."

As percepções entre as pessoas são diferentes, no entanto é possível obter e delimitar, por exemplo, pontos de convergência entre grupos. O diagnóstico das preferências, valores e atitudes tende a oferecer subsídios que podem ajudar a traçar perfis de um grupo. Diagnosticar o entendimento e perspectivas dos estudantes do Ensino Médio Integrado e da Licenciatura em Geografia e como desdobramento no tratamento das temáticas físico-naturais (ANIZIA, 2018). 
Em levantamento realizado no Banco de Dados ERIC, principal banco de dados de língua inglesa sobre a educação, constataram que, em 30 anos (1966/1996), houve um aumento na ordem de 700\% em referências bibliográficas sobre os saberes docentes. Esses autores observaram, na análise de boa parte desses trabalhos, uma alteração no modelo de formação de professores em vigor. Os novos princípios estabelecidos indicam que os saberes da ação constituem o quadro de referência para as discussões a respeito da formação docente, destacaram que, em artigos e periódicos publicados no Brasil entre 1990 e 1996, a temática relativa aos saberes docentes ganhou destaque e Pesquisadores em Geografia Física Ensino de Geografia.

Todavia, isso não foi observado nas teses e dissertações defendidas entre 1992 e 1996, nas quais sobressaíram os temas relativos à formação inicial e à continuada, e nos GTs da Associação Nacional e Pós-Graduação e Pesquisa em Educação (ANPED), realizados entre I992 e I998, nos quais a ênfase foi a formação inicial. Como resultado desse levantamento, os autores apontam uma grande quantidade de discursos sobre os saberes docentes e, por outro lado, uma escassez de dados empíricos para subsidiar as práticas e as políticas educacionais (TARDIF,200I).

Fonte: Autor

\section{I.I Problematização do lugar por Meio das Temáticas Físico-Ambientais}

Problemas relacionados à má formação docente colaboram para a dificuldade de tratar didática e pedagogicamente os conteúdos/conceitos usados em Geografia no âmbito da educação básica. Entretanto, o desconhecimento da Geografia local, e suas respectivas especificidades físico-ambientais, agravam essa situação. No Distrito Federal, nosso campo de trabalho, pesquisas indicam uma desconexão da prática pedagógica dos professores com o lugar, com ênfase e exemplos relacionados a aspectos distantes, desvinculados do cotidiano (BIZERRIL e FARIA, 2003; SILVA, 2015; LEITE, 2012). 
Não conhecer o lugar de vivência dos alunos pode gerar um distanciamento do discurso do professor em relação as suas narrativas e práticas sociais. Sendo assim, os conteúdos/conceitos relativos às temáticas físico-ambientais, se trabalhados de modo a não dialogar com os alunos e/em seus espaços, continuará padecendo da fragmentação própria de uma abordagem tradicional do ensino. As conexões que podem ser feitas a partir do lugar o valorizam, ao mesmo tempo, que viabiliza uma leitura da extensão da espacialidade do que se percebe no imediato. Neste sentido, complementa que o "lugar é a síntese das relações que o configuram e que por ele são configuradas, constituindo-se no lócus privilegiado à compreensão da complexidade socioambiental" (SANTOS 2006, p.17).

Nos grupos focais a ambas as turmas foram perguntadas se os conteúdos eram problematizados a partir lugar, se conseguiam fazer relações entre o que aprendiam e o que viam no dia a dia. As respostas revelaram que não, mesmo os alunos que responderam positivamente não conseguiram desenvolver a ideia ou ilustrar o raciocínio com algum exemplo

\section{CONCLUSÃO}

Neste artigo se pode constatar da experiência em sala de aula e por pesquisa bibliográfica que processo de ensino e aprendizagem acerca dos números irracionais, é necessário um aprofundamento, de modo a, perceber a construção dos números reais, bem como a construção dos campos numéricos relativos ao entendimento dos números irracionais sendo tratado com maior relevância neste trabalho

É fundamental que ao trabalhar qualquer tema e/ou conteúdo não só da Geografia, como de qualquer outra área, o docente deixe explícito para os discentes quais são os objetivos do trabalho e como o mesmo será desenvolvido, destacando o conteúdo aplicado ao conhecimento diário desse aluno, levando- o a correlação com o cotidiano que é o objetivo da geografia. 
Os estudantes são o centro da ação educativa, por isso devem ser convidados ao debate, à participação constante e não serem colocados como expectadores passivos do processo.

O tratamento de temas e/ou conteúdo da Geografia e de suas subáreas devem estar relacionados à faixa etária do público alvo, às questões amplas e específicas do cotidiano; precisa estar vinculado à intencionalidade consciente do docente quanto à abordagem escolhida e proposta; além de estar balizado por uma ação dinâmica, crítica e reflexiva. A Geografia é de fato uma ciência que pode contribuir para a compreensão e ação do/no espaço geográfico, dependendo da forma como é vista e utilizada.

Logo, se verifica a necessidade de mudança na formação dos futuros docentes, tendo a necessidade de rever a relação professor-aluno, com um conhecimento de ensino diretivo; a autoridade intelectual do professor em relação ao conhecimento geográfico e pedagógicodidático; a necessidade de tratar os conteúdos considerando a realidade e estabelecendo uma relação entre o local e o global; a importância da realização de trabalhos de campo de modo que favoreçam o diálogo profícuo entre teoria e prática

\section{REFERENCIAS}

BIANCHINI, B. L.; MACHADO, S. D. A. A Dialética entre Pensamento e Simbolismo Algébricos. Educação Matemática Pesquisa, v. I2, n. 2, p. 354-368, 2010.

BOYER, C. B. História da matemática; tradução: Elza F. Gomide. São Paulo, Edgard Blucher,1974.

CLAUDINO-SALES, V. Geografia, sistemas e análise ambiental: abordagem crítica. Revista Geousp - Espaço e Tempo, São Paulo, v. I6, p. I25-145, 2004. Diário do Nordeste. Disponível em: . Acesso em o5 ago 2019. 


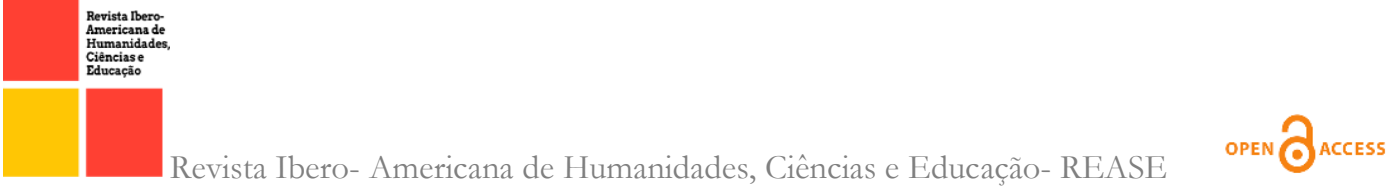

DINIZ, M. T. M.; SILVA, S. D. R. O Método Indutivo e a pesquisa em Geografia: aplicação no mapeamento de unidades da Paisagem. CADERNO DE GEOGRAFIA, v. 28, p. 731-745, 2018.

MENDONÇA. F. Geografia Socioambiental. Terra livre. São Paulo. № ı6, 20 II.

OLIVEIRA, Ivanilton José de. A cartografia na formação do professor de Geografia: análise da Rede Pública Municipal de Goiânia. IN: MORAIS, Eliana Marta Barbosa de; MORAES, Loçandra Borges de. (Orgs.) Formação de professores: conteúdos e metodologias no processo de ensino e aprendizagem. Goiânia: NEPEG, 2010. p.123-136.

VESENTINI, José Willian. Educação e ensino da Geografia: instrumentos de dominação ou libertação. In: CARLOS 